Supporting Information

\title{
Atomic Layer Deposition of MnS: Phase Control and Electrochemical Applications
}

Shannon C. Riha* ${ }^{\star} \S$, Alexandra A. Koegel ${ }^{\S}$, Xiangbo Meng ${ }^{\dagger}$, In Soo Kim*, Yanqiang $\mathrm{Cao}^{\dagger}$, Michael J. Pellin*, Jeffrey W. Elam ${ }^{\dagger}$, Alex B. F. Martinson*,*

${ }^{\S}$ Department of Chemistry, University of Wisconsin-Stevens Point, Stevens Point, WI 54481, United States.

${ }^{\dagger}$ Energy Systems Division, Argonne National Laboratory, Argonne, Illinois 60439, United States.

*Materials Science Division, Argonne National Laboratory, Argonne, Illinois 60439, United States.

*Email: sriha@uwsp.edu.

* Email: martinson@anl.gov. 

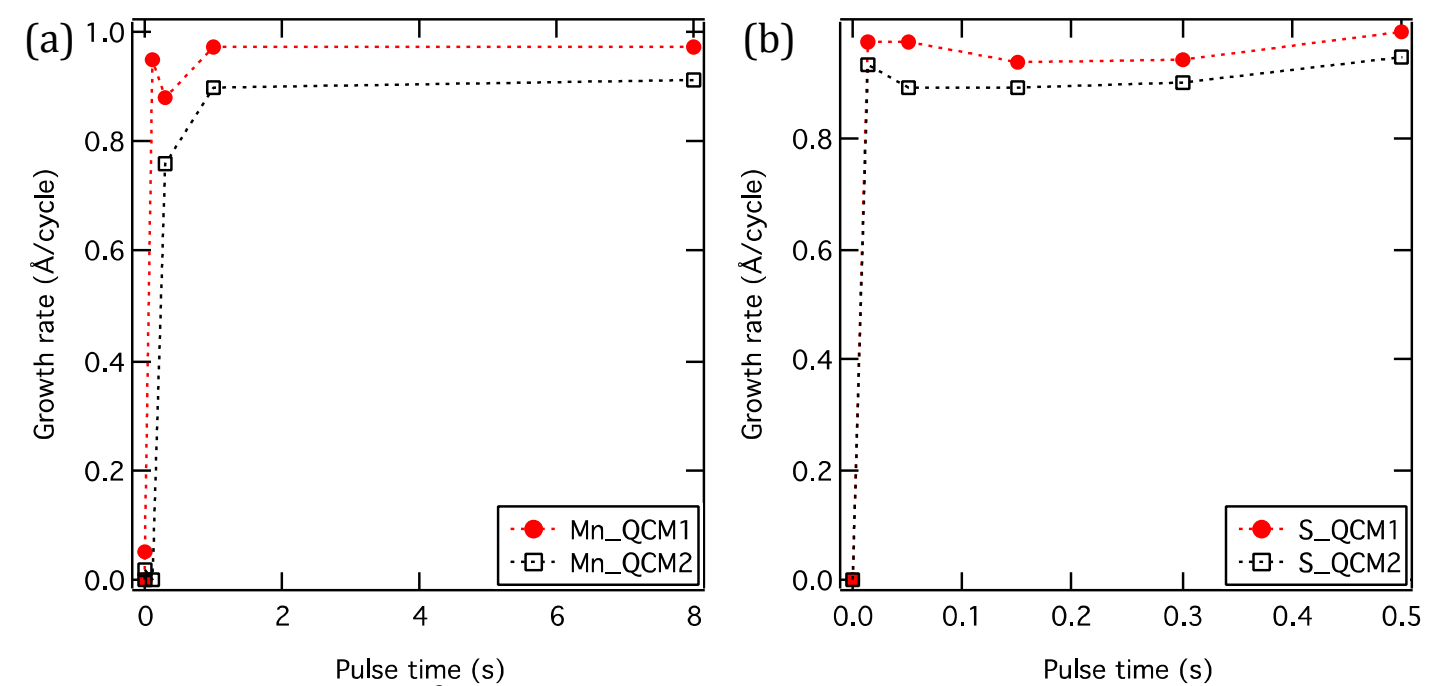

Figure S1. Growth rate $\left(\AA /\right.$ cycle) versus exposure time (s) at $150{ }^{\circ} \mathrm{C}$. (a) $\mathrm{Mn}(\mathrm{EtCp})_{2}$ sequence $x-15-0.1-15$, with $x$ being the exposure time of $M n(E t C p)_{2}$ (b) $\mathrm{H}_{2} \mathrm{~S}$ sequence $1-15-y-15$, with y being the exposure time of $\mathrm{H}_{2} \mathrm{~S}$.

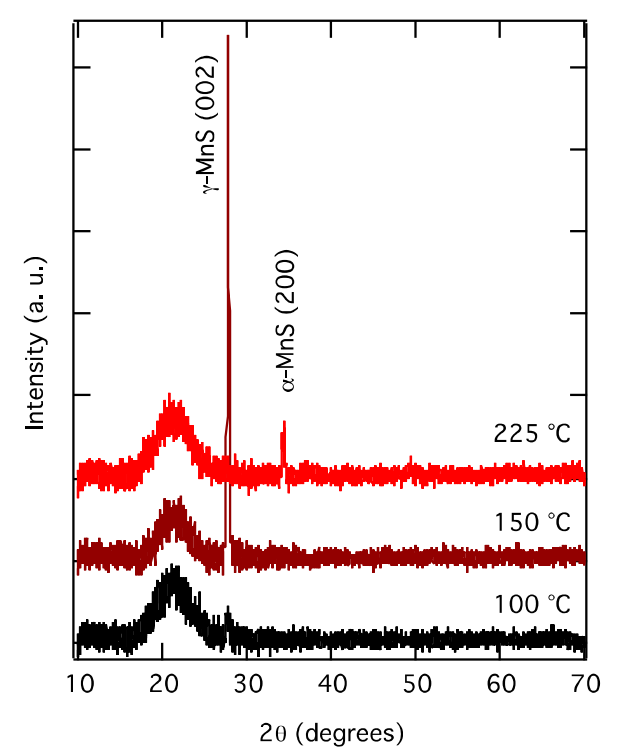

Figure S2. XRD patterns of ALD MnS on fused quartz substrates. 
(a)
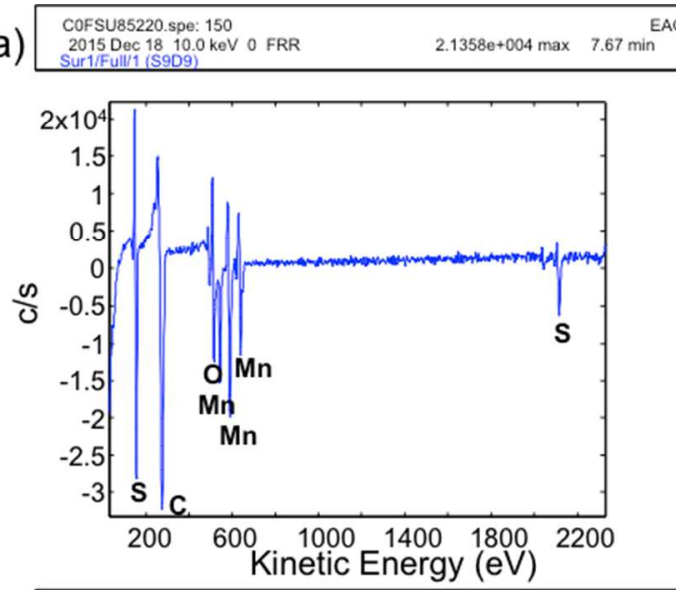

(b)
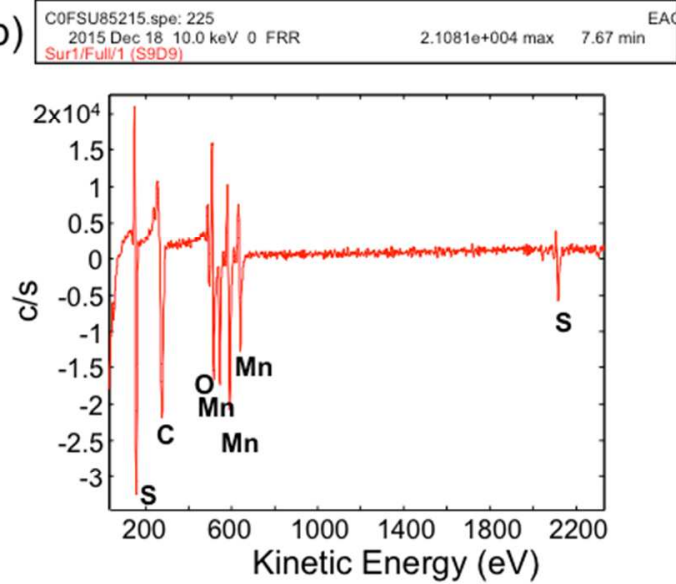

(c) \begin{tabular}{ll}
\hline COFSU85221.pro: 150 & EA \\
2015 Dec $1810.0 \mathrm{keV}$ O FRR & $3.83920+001 \max$
\end{tabular}

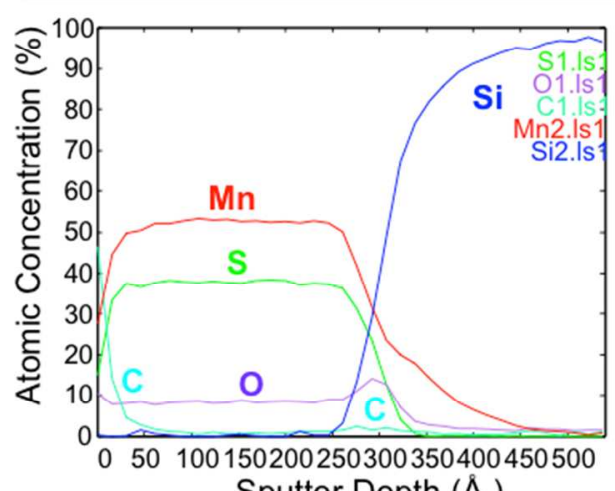
Sputter Depth $(\AA)$

(d)
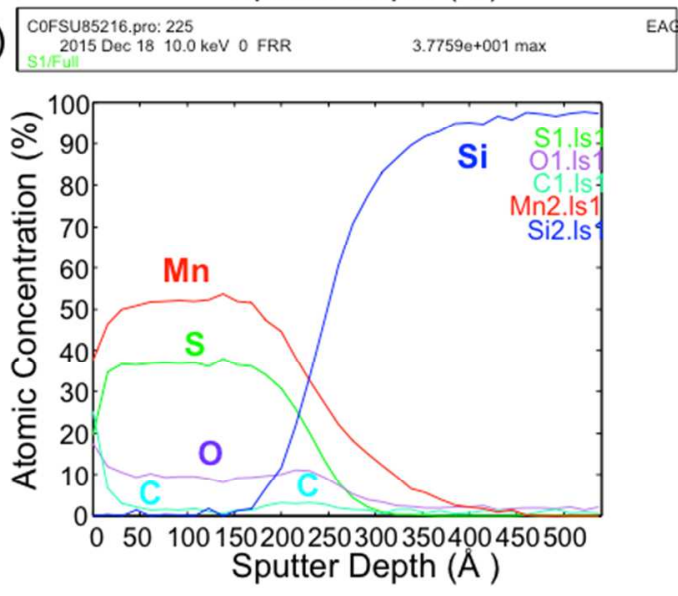

Figure S3. Auger electron spectroscopy of the surfaces of (a) $150{ }^{\circ} \mathrm{C}$ and (b) $225^{\circ} \mathrm{C}$ deposited MnS thin film. AES depth profile of the (c) $150{ }^{\circ} \mathrm{C}$ and (d) $225^{\circ} \mathrm{C}$ thin film. The data shows the presence of $\mathrm{C}, \mathrm{O}, \mathrm{Mn}$, and $\mathrm{S}$ in these films. The $\mathrm{C}$ was found to be limited to the surface of the film and near the MnS/Si interface. The ratio of $\mathrm{Mn}: \mathrm{S}$ throughout both films was $\sim 1: 0.7$. The off-stoichiometry may be attributed to the 0 contamination likely resulting from exposure to ambient during sample transfer for chemical analysis. Taking the 0 into consideration, the $\mathrm{Mn}:(\mathrm{S}+0)$ is 1:1 suggesting Mn retains the +2 oxidation state. 

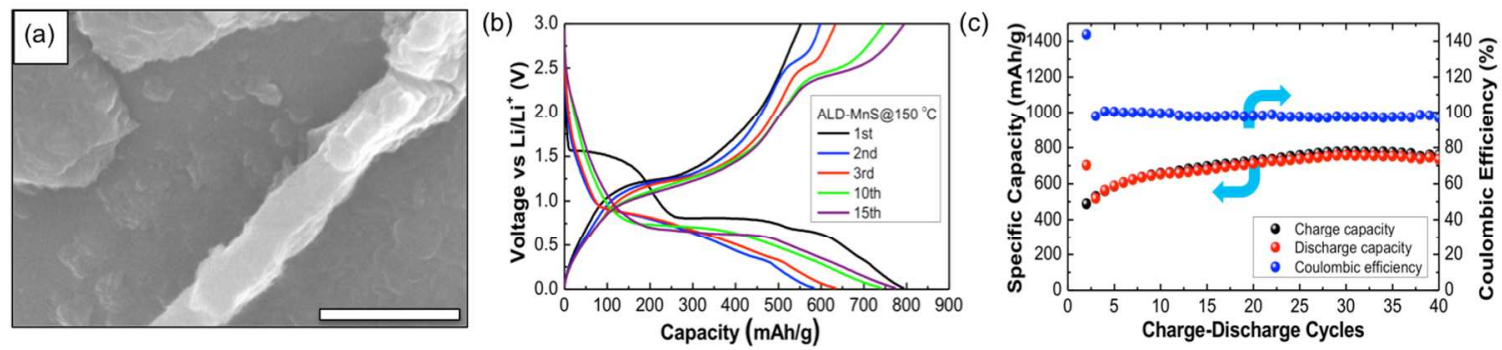

Figure S4. SEM and electrochemical data for ALD-MnS thin films deposited on Cu foil at $150{ }^{\circ} \mathrm{C}$. a) SEM image showing the cross-section from a delaminated piece of MnS thin film. Scale bar $=500 \mathrm{~nm}$ b) Charge-discharge profile for the $1^{\text {st }}, 2^{\text {nd }}, 3^{\text {rd }}, 10^{\text {th }}$, and $15^{\text {th }}$ cycle using an applied current of $100 \mathrm{~mA} / \mathrm{g}$ and a voltage window of $0.01-3.0$ $\mathrm{V}$ vs $\mathrm{Li} / \mathrm{Li}^{+}$. c) Cycling data showing capacity (left axis, red and black traces) and Coulombic efficiency (right axis, blue trace).

(a)

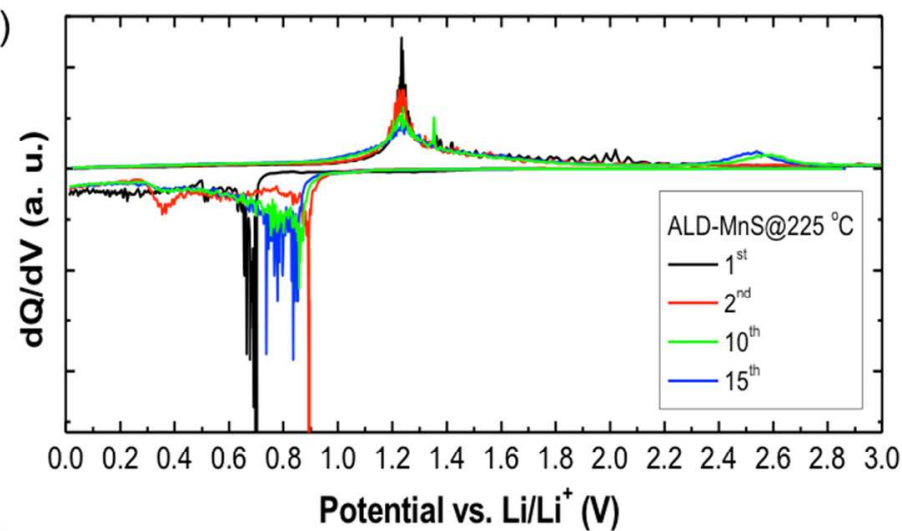

(b)

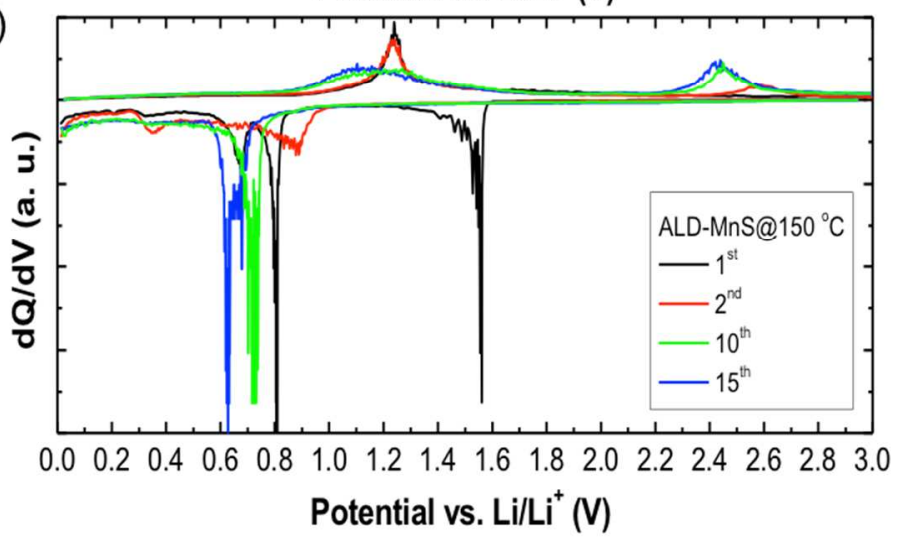

Figure S5. dQ/dV profiles of ALD-MnS deposited at (a) 225 and (b) $150{ }^{\circ}$ C. 